\title{
Investigation of $\mathrm{Zr}(\mathrm{IV})$ and ${ }^{89} \mathrm{Zr}(\mathrm{IV})$ complexation with hydroxamates: Progress towards designing a better chelator than desferrioxamine $B$ for immuno-PET imaging
}

\author{
François Guérard ${ }^{a}$, Yong-Sok Lee ${ }^{b}$, Raphaël Tripier ${ }^{c}$, Lawrence P. Szajek ${ }^{d}$, Jeffrey R. \\ Deschamps $^{e}$, and Martin W. Brechbiel ${ }^{\star}, a$ \\ aRadioimmune \& Inorganic Chemistry Section, Radiation Oncology Branch, NCl, NIH Bethesda, \\ Maryland 20892, USA \\ ${ }^{b}$ Center for Molecular Modeling, Divison of Computational Bioscience, Center for Information \\ Technology, National Institutes of Health, Bethesda, MD 20892, USA \\ 'CNRS, UMR 6521, Université de Brest, Laboratoire de Chimie, Electrochimie Moléculaires et \\ Chimie Analytique, 6 Avenue Victor Le Gorgeu, 29200 Brest, France \\ dPositron Emission Tomography Department, Warren Grant Magnuson Clinical Center, National \\ Institutes of Health, Bethesda, Maryland, USA \\ eenter for Bio/Molecular Science and Engineering, Code 6900, U.S. Naval Research \\ Laboratory, Washington, DC 20375, USA
}

\begin{abstract}
Single crystal X-ray diffraction show that $\mathrm{Zr}$ (IV) forms an octa-coordinated complex with 4 bidentate hydroxamates whose solution structures were investigated utilizing density functional theory at the level of B3LYP/DGDZVP. Stability constants obtained by potentiometry were in accordance with the tendency observed when radiolabeling with ${ }^{89} \mathrm{Zr}$.
\end{abstract}

The positron-emitter ${ }^{89} \mathrm{Zr}$ exhibits favorable physical characteristics for applications in nuclear imaging, especially when associated with a cancer targeting antibody. Its $78.4 \mathrm{~h}$ half-life matches the biodistribution kinetics of full antibodies, allowing for the achievement of high tumor-to-background signal ratio a few days after administration. Recent pre-clinical and clinical studies have shown the high potential of this radionuclide, ${ }^{1}$ and the relatively low cost and simplicity of production makes ${ }^{89} \mathrm{Zr}$ a serious challenger to ${ }^{124} \mathrm{I}\left(\mathrm{T}_{1 / 2}=100.2\right.$ h), a more costly and extensively investigated $\beta^{-}$-emitter. ${ }^{2}$

Currently, antibody radiolabeling with ${ }^{89} \mathrm{Zr}$ is performed via the Desferrioxamine B chelator (DFB), a siderophore bearing 3 hydroxamate units coordinated to the metal (Fig. 1). ${ }^{3}$ However, while use of DFB has allowed radiolabeling of antibodies with ${ }^{89} \mathrm{Zr}$ in proof-ofconcept studies, concerns remain regarding the in vivo stability of this complex. This instability has been observed in several animal studies with uptake of ${ }^{89} \mathrm{Zr}$ in bone when release from the chelate occurs. ${ }^{4}$

(O)The Royal Society of Chemistry

Fax: 301-402-1923; Tel: 301-496-0591; martinwb@mail.nih.gov.

$\dagger$ Electronic Supplementary Information (ESI) available: Details of syntheses, NMR study, crystallographic study, quantum chemical calculation, potentiometry and radiochemistry as well as crystallographic data in CIF format. See DOI: 10.1039/b000000x/ 
While several works have focused on the modification of the linkage between the DFB and the antibody, ${ }^{3,5}$ no attempts to improve the chelator itself have been reported. Yet, with only 3 hydroxamate donor groups, DFB does not appear to be ideal to saturate the coordination sphere of $\mathrm{Zr}^{4+}$. In contrast, a chelator with 4 hydroxamates that would form an octacoordinated complex with this cation would reasonably be expected to be more appropriate for this application.

The medium sized and highly charged $\mathrm{Zr}^{4+}$ (ionic radius $=0.84 \AA$ ) ${ }^{6}$ is a hard cation exhibiting a strong affinity for anionic oxygen donors. Particularly, hydroxamates have been known as good ligands for this cation for decades. ${ }^{7}$ However, there is a dearth of data concerning the complexation chemistry of $\mathrm{Zr}^{4+}$ with hydroxamates from the structural and thermodynamic point of view. To our knowledge, no X-ray structures have been reported and stability constants of the previously investigated complexes are either incomplete or unknown.

In this study, we aim to provide new data regarding this specific type of complex that should assist in the rational design of hydroxamate-based chelating agents for ${ }^{89} \mathrm{Zr}^{4+}$. We initiated this work with 2 simple hydroxamic acids: acetohydroxamic acid (AHA) and $N$-methyl acetohydroxamic acid (Me-AHA) (Fig. 1). The presence of a methyl at the carbonyl and nitrogen positions makes Me-AHA the simplest and the most electronically similar ligand to binding sites provided by DFB. The desired complexes were obtained by ligand exchange from $\mathrm{Zr}(\mathrm{IV})$ acetylacetonate in the presence of excess of hydroxamic acid (4.1 eq.) in refluxing methanol. After isolation, crystallization of $\mathrm{Zr}(\mathrm{Me}-\mathrm{AHA})_{4}$ was successful from dichloromethane/nitrobenzene (5/1), allowing for the determination of the crystal structure by X-ray diffraction.

Single-crystal x-ray diffraction data were collected at $150 \mathrm{~K}$ using MoKa radiation and a Brüker APEX 2 CCD area detector. The final anisotropic full matrix least-squares refinement on $\mathrm{F}^{2}$ with 363 variables converged at $\mathrm{R} 1=3.48 \%$ for the observed data. To our knowledge, this is the first time that the $\mathrm{X}$-ray structure of a $\mathrm{Zr}$ complex with this class of ligands is reported. The X-ray structure shows that the metal is octa-coordinated by 4 hydroxamates via their oxygen atoms (Fig.2). The coordination by each pair of oxygen exhibits a relatively high symmetry with $\mathrm{Zr}-\mathrm{O}$ distances of about $2.2 \AA$. However, analysis of the X-ray data suggests that the ligands are disordered such that the $\mathrm{N}$ and $\mathrm{C}$ atoms may swap positions. As a result, the averaged structure obtained exhibits some non-ideal bond lengths (e.g. $\mathrm{N}-\mathrm{CH}_{3}(1.485 \AA)>\mathrm{C}-\mathrm{CH}_{3}(1.464 \AA)$ in fragment A). Attempts to resolve this disorder by refining the occupancy of the $\mathrm{N}$ and $\mathrm{C}$ atoms with the methyl substituent did not provide noticeable improvement, probably due to a disorder affecting actually all the ligands.

Consequently, in order to refine the bond lengths, and also to better understand the bonding nature of $\mathrm{Zr}^{4+}$ with the hydroxamate ligands in solution, quantum chemical calculations at the B3LYP/DGDZVP level ${ }^{8}$ in the reaction field of water were carried out from this X-ray structure. The resulting calculated complex closely resembles the X-ray structure with a heavy atom root mean square deviation of $0.28 \AA$ (Fig. S1 in ESI $\dagger$ ). Whereas the calculated average bond distance of the $\mathrm{Zr}-\mathrm{ON}(2.199 \AA)$ is shorter than the $\mathrm{Zr}-\mathrm{OC}(2.324 \AA)$, these two respective average distances are very comparable in the X-ray structure (2.183 and $2.204 \AA$ ). In a similar hydroxamate-based structure of tetrakis $(N$-benzoyl- $N$ phenylhydroxylaminato)hafnium(IV) or $\mathrm{Hf}(\mathrm{NBPHA})_{4}$ reported by Tranqui et al, ${ }^{9}$ the average distance of $\mathrm{Hf}-\mathrm{ON}(2.116 \AA)$ is shorter than Hf-OC $(2.258 \AA)$. This strongly suggests that the $\mathrm{Zr}-\mathrm{ON}$ bond distance is shorter than $\mathrm{Zr}-\mathrm{OC}$ as observed in the calculated structure. Also, the discordance between the $\mathrm{C}-\mathrm{CH}_{3}$ and the $\mathrm{N}-\mathrm{CH}_{3}$ bond lengths observed for the X-ray structure was resolved in the calculated structure $(1.509 \AA$ and $1.454 \AA$ for all 
$\mathrm{C}-\mathrm{CH}_{3}$ and $\mathrm{N}-\mathrm{CH}_{3}$, respectively). Another quantum chemical calculation after replacement of $\mathrm{Hf}$ by $\mathrm{Zr}$ and NBPHA by Me-AHA in the X-ray structure of $\mathrm{Hf}(\mathrm{NBPHA})_{4}$ resulted in a conformer $0.7 \mathrm{kcal} / \mathrm{mol}$ less stable than the one calculated from the X-ray structure (Fig. $\mathrm{S} 2 \dagger)$, suggesting the probable co-existence of these two conformers of $\mathrm{Zr}(\mathrm{Me}-\mathrm{AHA})_{4}$ in solution. Both calculated coordinates are given in Tables $\mathrm{S} 1$ and $\mathrm{S} 2 \dagger$.

The NMR study of both $\mathrm{Zr}(\mathrm{Me}-\mathrm{AHA})_{4}$ and free ligand Me-AHA was also carried out in order to probe their dynamics in solution. The experimental ${ }^{1} \mathrm{H}$ and ${ }^{13} \mathrm{C}$ NMR spectra of the free ligand (Fig. S4 $\dagger$ ) show the presence of $Z$ and $E$ rotamers of Me-AHA at room temperature due to the hindered rotation with respect to the $\mathrm{C}-\mathrm{N}$ amide bond. Quantum chemical calculation at the B3LYP/6-31G* level in the reaction field of $\mathrm{CHCl}_{3}$ indicated that the $Z$ form is more stable than $E$ by $0.4 \mathrm{kcal} / \mathrm{mol}$ (Structures and coordinates in Fig. S3, Tables $\mathrm{S} 3$ and $\mathrm{S} 4 \dagger$ ). This was confirmed by the presence of a slight excess of the $\mathrm{Z}$ form in the experimental ${ }^{1} \mathrm{H}$ spectrum, with a ratio of $52 / 48$ for the integration of the $\mathrm{N}-\mathrm{CH}_{3}$ split signal. Based on the calculated energetics together with the experimental NMR data, both rotamers were fully characterized. For example, the $N$-methyl carbon of the $E$ form $s y n$ to oxygen ( $\delta 36.14$ ) is better shielded than the anti carbon of the $Z$ form ( $\delta 36.89)$. This assignment is consistent with the previous ${ }^{13} \mathrm{C}$ NMR studies, which have shown that alkyl carbon atoms syn to amide oxygen are better shielded than the corresponding anti carbons. ${ }^{10}$ In line with these ${ }^{13} \mathrm{C}$ assignments, the two methyl peaks at $\delta 3.24$ and 3.37 are assigned to the $E$ and $Z$ of the $N-\mathrm{CH}_{3}$ respectively (Tables $\mathrm{S} 4$ and $\mathrm{S} 5 \dagger$ ). In contrast, all the ${ }^{1} \mathrm{H}$ and ${ }^{13} \mathrm{C}$ doublets associated with the $Z$ and $E$ rotamers of Me-AHA appear as a singlet in $\mathrm{Zr}(\mathrm{Me}-$ AHA) 4 since only the $\mathrm{Z}$ rotamer can form a bidentate complex with $\mathrm{Zr}^{4+}$ (Fig. S5 $\dagger$ ). This demonstrates the formation of $\mathrm{Zr}(\mathrm{Me}-\mathrm{AHA})_{4}$ in solution that is consistent with the present $\mathrm{X}$-ray structure. Additionally, these single peaks also strongly suggest that the two calculated conformers of $\mathrm{Zr}(\mathrm{Me}-\mathrm{AHA})_{4}$ derived from the X-ray structures, undergo rapid inter-conversion at room temperature that cannot be detected at the NMR time scale. As a result, the 4 methyl groups appear as equivalent.

To further explore the $\mathrm{Zr}$ affinity for hydroxamates, we assessed the complexation by potentiometric titrations in aqueous solutions $\left(0.10 \mathrm{M}\right.$ ionic strength in $\mathrm{KNO}_{3}$ at $\left.25^{\circ} \mathrm{C}\right)$. At first, the acid-base properties of AHA and Me-AHA were investigated. The calculated protonation constants, $\mathrm{pK}_{\mathrm{a}}=9.33$ and 8.75 obtained respectively for AHA and Me-AHA were in good agreement with the literature data. ${ }^{11}$ Next, we turned our attention to the complexation of $\mathrm{Zr}(\mathrm{IV})$. Based on the structure of the complex determined in the X-ray study, we performed potentiometric titrations for a 1:4 (M:L) adduct. Thus, metal ratio of approximately 0.25 equivalent of $\mathrm{Zr}$ (IV) (relative to the ligand amount) were used during complexation titrations, and the titration curves obtained were used jointly to refine the complete model of stability constants for all the complex species. However, different potential adducts from 1:4 to 1:1 metal-to-ligand complexation modes and the corresponding complex species have been considered. The data used for $\mathrm{Zr}$ hydroxides were taken from the literature and especially from the potentiometric study reported by Veyland et al. ${ }^{12}$ For both ligands, species of 1:4 stoichiometry were predominant in equilibrium on the studied $\mathrm{pH}$ scale $(\mathrm{pH}=2-12)$. A selection of calculated overall $(\log \beta)$ and stepwise $(\log K)$ stability constants is available in Table 1 . These values are in good agreement with the literature data for $\mathrm{Zr}(\mathrm{IV})$ hydroxamates complexes investigated by other experimental methodologies, 7,13 and are also in the same order of magnitude than those observed with $\mathrm{Fe}^{3+}$, known to form strong complexes with hydroxamic acids in various natural biological processes. ${ }^{11}$ Speciation diagrams calculated from the complexation constants are available in ESI (Fig. $\mathrm{S} 6 \dagger)$. Interestingly, $\log K$ values decrease in the order $\mathrm{ZrL}>\mathrm{ZrL}_{2}>\mathrm{ZrL}_{3}$, to finally reach a maximum for the $\mathrm{ZrL}_{4}$ species. Overall, these results illustrate the preference of these ligands to form 1:4 complexes with adequate metal concentrations and the stronger affinity of Me-AHA for $\mathrm{Zr}(\mathrm{IV})$ with higher $\log \beta$ values compared to AHA. 
The superiority of Me-AHA was confirmed by a complexation study with the radionuclide ${ }^{89} \mathrm{Zr}$. AHA and Me-AHA were incubated for $30 \mathrm{~min}$ at $50{ }^{\circ} \mathrm{C}$ with a ${ }^{89} \mathrm{Zr}$ oxalate solution (3.33 to $3.7 \mathrm{MBq}$ ) at $\mathrm{pHs}$ varying from 4 to 10 . The resulting mixtures were analyzed by ITLC-SG using a $50 \mathrm{mM}$ EDTA solution as eluant. DFB was also included in the study for comparison. It was by far the best ligand with $>99 \%$ of the activity complexed (activity remaining at the bottom of the TLC) for pHs ranging from 5 to 9 , due to the preorganization of the hydroxamates, while the best results with the single hydroxamates were obtained at $\mathrm{pH} 7$, with about $20 \%$ and only $3.5 \%$ activity bound to Me-AHA and AHA, respectively. The rest of the activity was spread along the TLC up to the top, and corresponded to either uncomplexed ${ }^{89} \mathrm{Zr}$, or progressively transchelated ${ }^{89} \mathrm{Zr}$ from the weaker hydroxamate ligands to the stronger chelator EDTA during the elution (Fig S7 $\dagger$ ). Even though it was not possible to determine the radiochemical yield of complex actually formed, this method of analysis proved Me-AHA to be better than AHA as observed in the potentiometry study described above. The higher localized charge on the oxygen atom at the nitrogen position provided by the methyl group in Me-AHA is probably the main reason of a stronger affinity for the metal, similarly to what has been reported for Fe(III) with this class of ligands. ${ }^{14}$

In conclusion, the X-ray and potentiometric data presented in this study open new perspectives for the synthesis of chelators for ${ }^{89} \mathrm{Zr}$. First, the fact that $\mathrm{Zr}$ (IV) forms octacoordinated complexes with the single hydroxamates strongly supports the hypothesis of the accessibility to a chelator better than DFB, if appropriately assembled from 4 of these subunit ligands. Secondly, it was observed that the coordination geometry of $\operatorname{Zr}(\mathrm{IV})$ with hydroxamate can be investigated at the B3LYP/DGDZVP level. This will allow for the design of hydroxamates-bearing chelators with an adequate pre-organization for the $\mathrm{Zr}(\mathrm{IV})$ cation. Lastly, the ability to measure stability constants of the investigated complexes by potentiometry as reported here for the first time allows for the rationalization of the stabilities observed for different ligands, and also provides a method for the exploration of alternative ligands to hydroxamates (i.e. catecholates and hydroxypyridinones) for the improved complexation of ${ }^{89} \mathrm{Zr}$. Research through the different axes of study opened here to improve the stability of the antibody radiolabeling with ${ }^{89} \mathrm{Zr}$ is warranted.

\section{Supplementary Material}

Refer to Web version on PubMed Central for supplementary material.

\section{Acknowledgments}

This work was supported by the Intramural Research Program of the NIH, National Cancer Institute, Center for Cancer Research and the Center for Information Technology. The quantum chemical study utilized PC/LINUX clusters at the Center for Molecular Modeling of the NIH (http://cit.nih.gov). X-ray crystallographic studies were supported by NIDA through Interagency Agreement \#Y1-DA1101 with the Naval Research Laboratory (NRL).

\section{Notes and references}

1. Zhang Y, Hong H, Cai W. Current Radiopharm. 2011; 4:131.

2. Chacko A-M, Divgi CR. Med. Chem. 2011; 7:395-412. [PubMed: 21711220]

3. Perk LR, Vosjan MJWD, Visser GWM, Budde M, Jurek P, Kiefer GE, van Dongen GAMS. Eur. J. Nucl. Med. Mol. Imaging. 2010; 37:250. [PubMed: 19763566]

4. Nayak TK, Garmestani K, Milenic DE, Brechbiel MW. J. Nucl. Med. 2012; 53:113. [PubMed: 22213822] van Rij CM, Sharkey RM, Goldenberg DM, Frielink C, Molkenboer JDM, Franssen GM, van Weerden WM, Oyen WJG, Boerman OC. J. Nucl. Med. 2011; 52:1601. [PubMed: 21865288] Holland JP, Divilov V, Bander NH, Smith-Jones PM, Larson SM, Lewis JS. J. Nucl. Med. 2010; 51:1293. [PubMed: 20660376] 
5. Verel I, Visser GWM, Boellaard R, Walsum MS, Snow GB, van Dongen GAMS. J. Nucl. Med. 2003; 44:1271-1281. [PubMed: 12902418] Tinianow JN, Gill HS, Ogasawara A, Flores JE,

Vanderbilt AN, Luis E, Vandlen R, Darwish M, Junutula JR, Williams S-P, Marik J. Nucl. Med. Biol. 2010; 37:289-297. [PubMed: 20346868] Zeglis BM, Mohindra P, Weissmann GI, Divilov V, Hilderbrand SA, Weissleder R, Lewis JS. Bioconjugate Chem. 2011; 22:2048-2059.

6. Shannon RD. Acta Crystallogr. A. 1976; 32:751-767.

7. Baroncelli F, Grossi G. J. Inorg. Nucl. Chem. 1965; 27:1085-1092.

8. Frisch, MJ., et al. Gaussian 09, revision A.02. Wallingford CT: Gaussian Inc.; 2009.

9. Tranqui D, Laugier J, Boyer P, Vulliet P. Acta Crystallogr. B. 1978; 34:767-773.

10. Lee Y-S, Siméon FG, Briard E, Pike VW. ACS Chem. Neurosci. 2012; 3:325-335. [PubMed: 22860199]

11. Codd R. Coord. Chem. Rev. 2008; 252:1387-1408.

12. Veyland A, Dupont L, Pierrard J, Rimbault J, Aplincourt M. Eur. J. Inorg. Chem. 1998; 1998:1765-1770.

13. Matteson BS, Tkac P, Paulenova A. Separ. Sci. Technol. 2010; 45:1733-1742.

14. Brink CP, Crumbliss AL. Inorg. Chem. 1984; 23:4708-4718. 

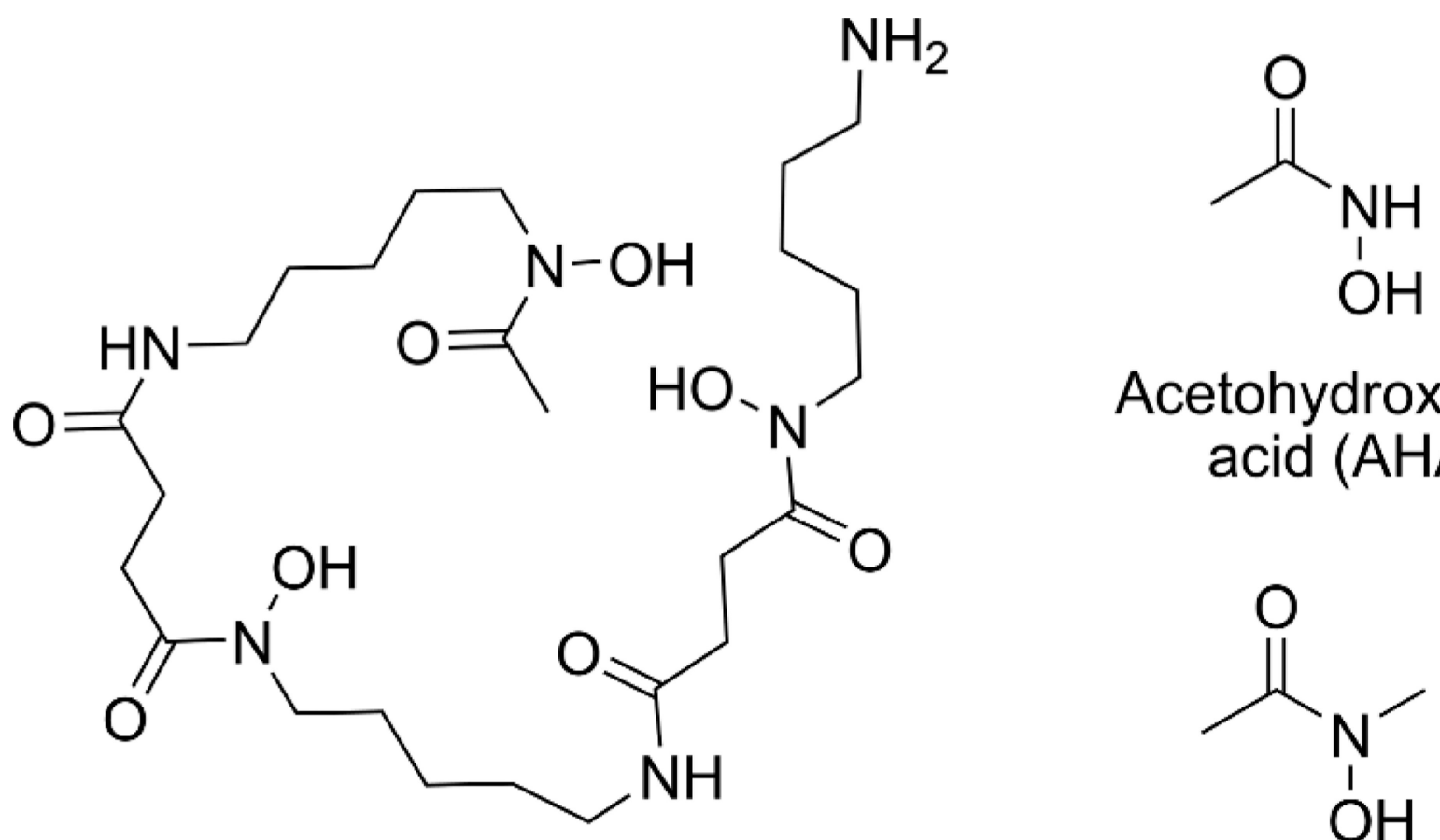

\section{Acetohydroxamic acid (AHA)}

\section{Desferrioxamine B (DFB)}

\section{$N$-methyl acetohydroxamic acid (Me-AHA)}

Figure 1.

Compounds discussed in this work. 


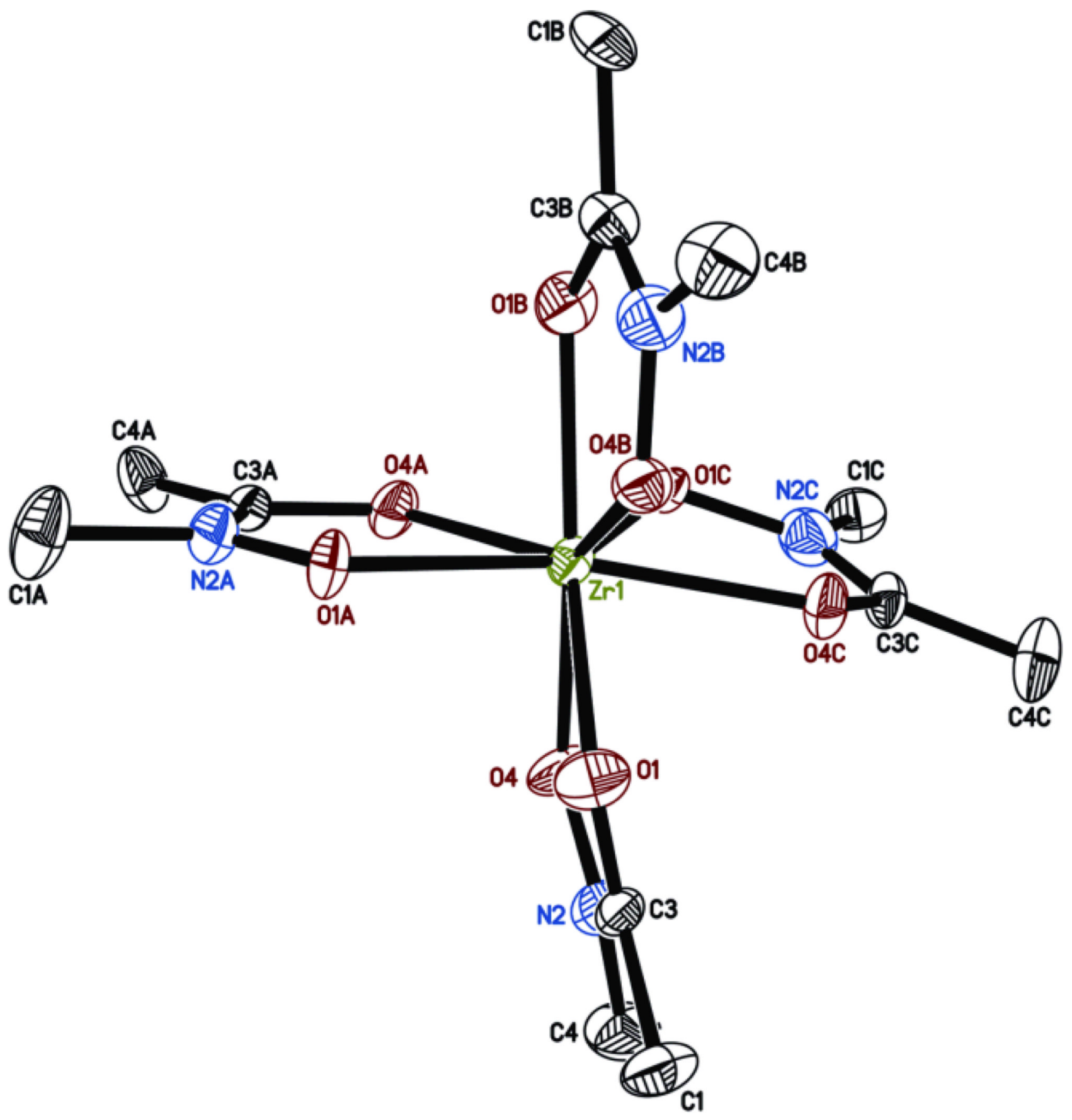

Figure 2.

X-ray structure of $\mathrm{Zr}(\mathrm{Me}-\mathrm{AHA})_{4}$ obtained from the $0.572 \times 0.258 \times 0.097 \mathrm{~mm}^{3}$ crystal. Displacement ellipsoids are shown at the 50\% level, hydrogen atoms and water molecules have been omitted for clarity. Space group $C c$, unit cell dimensions: $\mathrm{a}=17.8295(12), \mathrm{b}=$ 14.3111(14), $\mathrm{c}=13.2223(8) \AA$, and $\beta=129.061(2)^{\circ}$. Selected bond lengths $[\AA]$ and angles [ ${ }^{\circ}$ ]: Zr-O1 2.233(4), Zr-O4 2.196(3), Zr-O1A 2.215(3), Zr-O4A 2.172(5), Zr-O1B 2.189(4), Zr-O4B 2.163(5), Zr-O1C 2.178(4), Zr-O4C 2.199(3), O1-Zr-O4 69.6(1), O1A-Zr-O4A 70.4(1), O1B-Zr-O4B 68.4(1), O1C-Zr-O4C 69.3(1). 
₹Atomic coordinates for $\mathrm{Zr}(\mathrm{Me}-\mathrm{AHA}) 4$ have been deposited at the Cambridge Crystallographic Data Centre (deposition number 902586).

Chem Commun (Camb). Author manuscript; available in PMC 2014 February 03. 


\section{Table 1}

Overall and stepwise stability constants of the $\mathrm{Zr}(\mathrm{IV})$ complexes of AHA and Me-AHA $\left(25.0^{\circ} \mathrm{C}, \mathrm{I}=0.1 \mathrm{M}\right.$ in $\mathrm{KNO}_{3}$ ).

\begin{tabular}{ccccc}
\hline & \multicolumn{2}{c}{ AHA } & \multicolumn{2}{c}{ Me-AHA } \\
Species ${ }^{\boldsymbol{a}}$ & $\log \boldsymbol{\beta}$ & $\log \boldsymbol{K}^{\boldsymbol{b}}$ & $\log \boldsymbol{\beta}$ & $\log \boldsymbol{K}^{\boldsymbol{b}}$ \\
\hline $\mathrm{ZrL}$ & 12.01 & $12.01(3)$ & 13.21 & $13.21(2)$ \\
$\mathrm{ZrL}_{2}$ & 24.00 & $11.99(2)$ & 25.22 & $12.01(2)$ \\
$\mathrm{ZrL}_{3}$ & 29.69 & $5.69(5)$ & 28.66 & $3.44(5)$ \\
$\mathrm{ZrL}_{4}$ & 45.07 & $15.38(3)$ & 45.98 & $17.32(1)$ \\
\hline \multicolumn{5}{c}{} \\
${ }^{a}$ Charges are omitted for clarity. \\
\multicolumn{2}{c}{ Values in parentheses are standard deviations in the last significant digit. }
\end{tabular}

